\section{EMBRYRIDDLE \\ Aeronautical University}

SCHOLARLY COMMONS
International Journal of Aviation, Aeronautics, and Aerospace

8-1-2015

\title{
Examining How Breakdowns in Pilot Monitoring of the Aircraft Flight Path
}

\author{
Robert Sumwalt \\ Embry-Riddle Aeronautical University Worldwide, robert.sumwalt@ntsb.gov \\ David Cross \\ Embry-Riddle Aeronautical University Worldwide, crossaf6@erau.edu \\ Dennis Lessard \\ Embry-Riddle Aeronautical University Worldwide, lessa08a@erau.edu
}

Follow this and additional works at: https://commons.erau.edu/ijaaa

Part of the Aerospace Engineering Commons, Aviation Safety and Security Commons, Communication Commons, and the Management and Operations Commons

\section{Scholarly Commons Citation}

Sumwalt, R., Cross, D., \& Lessard, D. (2015). Examining How Breakdowns in Pilot Monitoring of the Aircraft Flight Path. International Journal of Aviation, Aeronautics, and Aerospace, 2(3). https://doi.org/10.15394/ ijaaa.2015.1063

This Article is brought to you for free and open access by the Journals at Scholarly Commons. It has been accepted for inclusion in International Journal of Aviation, Aeronautics, and Aerospace by an authorized administrator of Scholarly Commons. For more information, please contact commons@erau.edu. 
This research examined how ineffective monitoring of flight path can adversely affect aviation safety. Monitoring of the flight path is accomplished by effecting scanning of flight instruments and cockpit indications to derive information pertaining to aircraft energy state and trajectory. These instruments include: attitude indicator, airspeed indicator, vertical speed indicator, altimeter, navigation instruments, and flight mode annunciations. To better understand the failure of pilots to monitor flight path, this study focused on literature addressing human factors, and analyzed accident and incident data supporting both this study and the supporting literature. This study yielded useful recommendations for air carriers to implement the stipulations by the Federal Aviation Administration (FAA) which require specific training in monitoring for pilots.

The National Transportation Safety Board (NTSB) has long identified ineffective flight path monitoring to be problematic. A seminal crash occurred in December 1972, when the flight crew of an Eastern Airlines Lockheed 1011 crashed into the Florida Everglades. According to NTSB (1973), while attempting to replace a faulty landing gear indicator light, one of the flight crewmembers inadvertently bumped the control column, forcing the autopilot out of the altitude hold mode and placing it into a gradual descent. The crew's preoccupation with replacing the jammed light assembly took more than four minutes. Thus, the crew did not notice the descent into the dark, featureless terrain. The aircraft careened into the Everglades, claiming 99 lives (NTSB).

NTSB continued to note problems with ineffective monitoring. In 1994, NTSB released a safety study of crew-involved air carrier accidents. That study, which looked at 37 air carrier accidents that occurred between 1978 and 1990, found that ineffective monitoring and challenging was a factor in 31 of the 37 (84\%) reviewed accidents (NTSB, 1994). In that safety study, NTSB recommended that the FAA train pilots to use better monitoring techniques (NTSB, 1994).

In spite of that recommendation seemingly being accepted by stakeholders in response to the NTSB, we identified 17 accidents where poor monitoring was a factor, and which occurred since the NTSB's study period (1990). These results suggest that improved monitoring will require more work.

In response to a safety recommendation issued by NTSB in November 2013, the Federal Aviation Administration (FAA) published a final training rule that will require air carriers to incorporate explicit training pertaining to improving monitoring (National Archives and Records Administration, 2013). Airlines must incorporate this training into their programs no later than March 2019 to meet compliance standards (National Archives and Records Administration, 2013). 
In spite of training requirements for monitoring established by the aforementioned regulation, requirement for training for monitoring, our literature review found that more research is needed to determine how to train pilots to be more effective at monitoring (NTSB, 2009).

Given that 1) dozens of aircraft accidents have demonstrated that ineffective flight path monitoring poses an unacceptable risk to aviation safety; 2) between now and 2019, air carriers will be required to train pilots to more effectively monitor; and 3) more research is needed to determine how to train pilots to be better at monitoring, this research examined issues that can adversely affect flight crew monitoring of the flight path. Findings of this research were used to formulate recommendations to facilitate training of flight path monitoring.

\section{Scope and Limitations}

The goal of this research was to better understand factors that can lead to pilots' ineffectiveness at monitoring the aircraft flight path. The research focused on understanding those cases in which the aircraft flight path was not sufficiently monitored, leading to flight path deviations. Cases involving inadequate monitoring of radio communications, intra-cockpit communications, traffic, and aircraft systems were not within the scope of the study. Only accidents and incidents where the aircraft has two or more pilots were studied; events involving single pilots were not studied.

\section{Objective}

The objective of this research was to yield a greater understanding of factors leading to ineffective flight path monitoring, thus formulating useful recommendations to be employed by air carriers that will birth successful monitoring techniques in their aircrews. An extensive literature review was conducted to better understand human factors that can lead to ineffective flight path monitoring. Additionally, data were extracted from aircraft accident reports and incident reports that were submitted to the National Aeronautics and Space Administration's (NASA) Aviation Safety Reporting System (ASRS). These analyses derived information pertaining to the phase of flight in which the flight path deviation occurred, who or what detected the deviation (if detected at all), factors that contributed to the deviation, and the ensuing consequences (e.g., loss of separation, loss of control, altitude deviation). 
The following hypotheses were established and tested:

H1A: There is a statistically significant difference between accidents and non-accidents in this study's dataset regarding which pilot was the "pilot flying" (PF) when inadequate monitoring led to a flight path deviation.

H10: There is no statistically significant difference between accidents and non-accidents in this study's dataset regarding which pilot was the "pilot flying" (PF) when inadequate monitoring led to a flight path deviation.

$\mathrm{H} 2 \mathrm{~A}$ : There is a statistically significant difference between who or what detected the flight path deviation.

$\mathrm{H} 20$ : There is no statistically significant difference between who or what detected the flight path deviation.

\section{Literature Review}

A variety of exigent literature was reviewed to reveal limiting human factors and obstacles to effective monitoring. Topics reviewed included workload, inattentional blindness, change blindness, vigilance, and the effects of flight deck automation.

Raby and Wickens (1994) examined how pilots strategically planned workload and allocated tasks to accommodate increasing workload. Their review of several sources found that "breakdowns in task management do occur, and may at times be responsible for dangerous in-flight incidents" (p. 215). They noted that crews who experienced the highest workload were those who had the greatest tendency to delay critical tasks until later in the flight. Similarly, the higher performing crews were those who performed tasks earlier. Jentsch, Martin, and Bowers (1997) had a similar finding in their study of ASRS reports, finding that in approximately one-third of the ASRS reports they reviewed, poor workload planning, and task execution led to failed flight path monitoring.

Multitasking, as explained by Wickens, Santamaria, \& Sebok (2013), can involve concurrent processing and serial processing. In concurrent processing, "attention is divided by sharing scarce, multiple resources in the brain" (Wickens et al., 2013, p. 763). Due to overload, the brain may be incapable of concurrent processing. At this point, it operates on serial processing, in which the brain switches back and forth between tasks (Wickens et al., 2013). While attempting to switch back and forth between tasks, the brain must attempt to select the 
information to attend to, process it, encode it into memory, and finally, store the information (National Safety Council, 2012). Different types of information stimuli engage different neural pathways. Because competing bits of information flow across different pathways, mental processing speed and capability is compromised. As a result, information may be dropped or omitted from processing (National Safety Council, 2012).

Wickens et al. (2013) illustrated how monitoring breakdowns can occur when someone devotes more time to non-monitoring tasks, such as troubleshooting a problem, and fails to switch back to monitoring. Several factors can influence how likely someone is to switch back to the ongoing task, including task inertia (the tendency to stick with more difficult task), priority, interest in the alternate task, and the salience of the reminder to return to the ongoing task (Wickens et al., 2013). Meta-analysis by Wickens et al. (2013) found that unknowingly sticking with the easier tasks is the most common mental strategy. Because monitoring isn't usually the most interesting or easiest task, it becomes the neglected task.

Loukopoulos, Dismukes, and Barshi (2009) noted "one of the most common forms of error during multitasking is forgetting to perform some intended action" (pp. xiii - xiv). Additionally these authors noted that:

a special case of forgetting to perform tasks is to become so preoccupied with one task that the individual inadvertently stops concurrent monitoring the status of other tasks. Even when monitoring does not drop out completely, the quality of monitoring may suffer and pilots may fail to notice changes in the status of the monitored system. (Loukopoulos et al., 2009, p. 4)

Experiments conducted by Mack and Rock (1998) found that one quarter of their test subjects did not perceive an object's presence, even though it was plainly in sight. They concluded that the phenomena of not "seeing" something that is plainly visible was not a function of sight, but rather, one of attention being elsewhere. That is, although the item was plainly there, the person was mentally attending to something else. Nikolic, Orr, and Sarter (2004) discussed how pilots can miss changes on their flight deck displays. For example, a pilot may notice a particular mode annunciation on the flight mode annunciator (FMA). If the pilot then directs his/her attention away from the FMA attend to something else, then looks back at the FMA, they may not notice a change of mode status on the FMA.

In terms of human ability to adequately process data in respect to workload, the Flight Safety Foundation (2014) noted that "the human brain has evolved for 
active engagement in individual tasks that are challenging or stimulating, yet is less effective at monitoring for events that so rarely occur" (p. 12). Warm, Parasuraman, and Matthews (2008) stated that "converging evidence using behavioral, neural, and subjective measures shows that vigilance requires hard mental work and is stressful" (p. 433). Teichner (1974) found that not only does probability of detecting something decrease over time, the degree of performance degradation can vary depending on the strength of the signal and personal motivations.

In a basic sense, humans are better at monitoring when in-the-loop (actively engaged in the control loop) than when out-of-the-loop (not actively engaged in the control loop) (Parasuraman, Mouloua, \& Malloy, 1996). Humans tend to be less aware of changes in the environmental or system states when those changes are under the control of another agent (whether that agent is automation or another human) than when they make the changes themselves" (Parasuraman, Sheridan, \& Wickens, 2000, p. 291).

During testimony at a 2009 NTSB public hearing that additional research is needed to determine how to train pilots to be more effective at monitoring it was noted that:

we also need to develop and train the specific techniques that pilots can use. It's not enough to say you're supposed to monitor A, B and C. We need to say how to do it or when to do and what techniques you can use .... As with many procedural issues, you have to start with the theory in the classroom, but that's not going to do much good. You've got to practice it repetitively until it's automatic and then you've got to check it (NTSB, 2009, pp. 583584).

\section{Method}

This research study obtained information from the literature of relevant material, and data collected through two primary means: analysis of reports submitted to ASRS, and a case analysis approach to extracting information from selected aircraft accident reports.

\section{Data coding and collection}

To collect relevant data from ASRS reports and aircraft accident reports, a Common Data Coding and Collection Form (CDCCF) was developed and utilized for each reviewed report. The $\mathrm{CDCCF}$ was used to code information pertaining to: 
- The flight phase in which the flight path deviation occurred

- The role of each pilot when inadequate monitoring led to a flight path deviation

- Activity the crew was engaged when the flight path deviation occurred

- Status of automation engage when the flight path deviation occurred

- Factors that contributed to the poor monitoring, such as: poor planning, workload, attention management, distraction, fatigue, and boredom/complacency

- Who/what first detected the flight path deviation; e.g., pilot, cockpit alerting device, or air traffic control agency or mechanism.

- Consequences of the inadequate monitoring, such as stall-inducing airspeed/angle-of-attack, course deviation, altitude deviation, loss of control, and loss of separation.

\section{ASRS Reports}

ASRS was established in 1976 to identify problematic issues within the U.S. National Airspace System (Aviation Safety Reporting System, 2014a). Pilots, air traffic controllers, mechanics, flight attendants, dispatchers, and anyone else interested in reporting potential safety-related problems may submit a report to ASRS (ASRS, 2014a). Since its inception, ASRS has received over one million reports and is considered "one of the world's largest sources of information on aviation safety and human factors" (ASRS, 2014a, p. 15).

A search of the ASRS database was conducted to seek reports submitted from pilots of aircraft with a maximum gross takeoff weight of 14,501 pounds or more, and were submitted to ASRS between 2000 and June 2014. The study included analysis of 110 ASRS reports.

Because the scope of this research is focused on errors in monitoring flight path, reports involving taxi path deviations were excluded from the study as well as cases involving inadequate monitoring of radio communications, intra-cockpit communications, traffic, aircraft systems, and anything else not directly related to monitoring flight path.

To test the aforementioned research hypothesis, a Chi Square Test of Independence was utilized. 


\section{Aircraft Accident Reports}

A case analysis approach was undertaken to further provide granularity into the issue of flight path deviations resulting from inadequate monitoring. The accident database consisted of 25 accident reports in which poor monitoring of flight path was cited by the official accident investigation authority. Of the 25 reviewed accidents, 22 were investigated by the NTSB. The remaining three were investigated by the accident investigation authorities from the countries where the crash occurred.

The reviewed accidents occurred between December 1972 and July 2013. These accidents collectively claimed 894 lives and incurred 180 serious injuries.

Ten of the accident aircraft were operating under 14 Code of Federal Regulations Part 121, five were operating under Part 135 as scheduled air carrier operations, six were operated as foreign air carriers, two were operated as ondemand charter flights under Part 135, and two were being operated under Part 91. Two of the Part 121 flights were being operated as cargo flights with no passengers. Each of these reports were read and data extracted using the CDCCF.

Fifteen accidents were Controlled Flight Into Terrain (CFIT), while 10 involved stalls followed by loss of control. In three of the loss of control events, the crew regained control of the aircraft before ground impact. There were no fatalities associated with those events.

To test the aforementioned research hypothesis, a Chi Square Test of Independence was utilized.

\section{Results}

\section{ASRS Reports}

The 110 collected ASRS reports were analyzed for commonalities and differences among data points.

Pilot role assignment. One of the research objectives was to determine if there may be an unexpected number of cases where one pilot was flying versus another. All but one report provided information regarding which pilot was flying. Of the 109 reports that provided information, the captain was the pilot PF in 61 reports (56\%) and the first officer was the PF in 48 reports (44\%). 
Flight phase. Table 1 depicts the flight phase in which the flight path deviation occurred. The data clearly show that in this review of ASRS reports, the vast majority of flight path deviations occurred in the combined flight phases of climb $(n=29)$, descent $(n=50)$, or on approach $(n=22)$. One-hundred and one of the 110 reports $(92 \%)$ fell into this category.

\section{Table 1}

Flight phase in which monitoring error occurred due to lack of flight path monitoring, as reported in 110 ASRS reports.

\begin{tabular}{lcc}
\hline Flight Phase & Frequency & Percent $(\%)$ \\
\hline Climb & 29 & 26 \\
Level Flight & 9 & 8 \\
Descent & 50 & 46 \\
Approach & 22 & 20 \\
Total & 110 & 100 \\
\hline
\end{tabular}

Activities. The research probed flight crew activities at the time the flight path deviation occurred. Seventy-eight of the 110 (70.9\%) reports provided information regarding activities the crew may have been involved in shortly before the flight path deviation occurred. Table 2 illustrates those activities. For brevity, only those activities that were cited in five or more cases are depicted. Therefore, the frequency total does not equal the total number of reports in which activities were reported (78). Additionally, the categories are not mutually exclusive; therefore, each report can include multiple reported distracting activities. For example, one report mentioned the crew was engaged in programming the Flight Management System (FMS), chart reading, and resetting altimeters at transition altitude. 
Table 2

Activities pilots were engaged in when a flight path deviation occurred, as reported in 78 of 110 ASRS reports.

\begin{tabular}{lcc}
\hline Activity & Frequency & Percentage $(\%)$ \\
\hline Programming FMS & 18 & 23.0 \\
Radio communications/PA & 18 & 23.0 \\
Searching for traffic/landmark & & 12.8 \\
Dealing with abnormal condition & 10 & 10.2 \\
Normal checklists & 8 & 9.0 \\
Chart Reading/approach briefing & 7 & 6.4 \\
\hline
\end{tabular}

Note. Reported activities are not mutually exclusive.

${ }^{a}$ One report mentioned the crew was searching for a landmark that was required to be seen on a charted visual approach.

Contributing factors. Reporters cited several contributing factors to the poor monitoring and subsequent flight path deviation. Of the 110 reports in the ASRS dataset, 92 provided information regarding factors that contributed. Table 3 depicts those contributing factors that were cited in five or more ASRS reports. 
Table 3

Contributing factors to flight path deviation, as cited by crews (reported in 92 of 110 ASRS reports): Factors that crews cited as being a contributing factor to their flight path deviation, as reported in 92 of 110 ASRS reports.

\begin{tabular}{lcc}
\hline Factor & Frequency & Percentage (\%) \\
\hline Distractions & 38 & 41.3 \\
Automation reliance & 23 & 25.0 \\
Fatigue & 18 & 19.5 \\
High workload & 12 & 13.0 \\
Complacency & 9 & 9.7 \\
Runway/arrival change & 6 & 6.5 \\
Rushing/time pressure & 5 & 5.4 \\
\hline
\end{tabular}

Note. Only those factors that were cited in five or more cases were included.

As stated, these categories are not mutually exclusive. Pilots used the word "distractions" in 38 ASRS reports, but in many cases the reasons for the distractions were captured in the other contributing factor categories (Table 3) or activities (Table 2). For example, in one report the pilot wrote that airspeed bled off to 220 knots in a climb instead of the intended 300 knots. The autopilot had somehow reverted to a vertical speed mode and neither pilot noticed it. The pilot mentioned that at 17,000 feet, they were given a clearance to climb to a higher altitude. They were simultaneously resetting altimeters at the transition altitude, and the captain was checking a maneuver capability chart to see if they were legal to accept a certain cruise altitude. The pilot wrote, "No excuse for getting that slow even due to these many distractions and duties that were going on at the same time" (ASRS, 2014b, record no. 914396).

Flight deck automation. Of the 110 reports in the ASRS dataset, 58 provided information about autopilot engage status. In 23 of the 110 reports, pilots provided evidence that they relied on automation to execute a task, and therefore, 
didn't monitor the flight path parameters. One pilot wrote that he expected the aircraft to begin a planned descent, but it did not. "We just got complacent and failed to monitor the flight progress just for that few minutes" (ASRS, 2014b, report no. 808249).

Two reports mentioned pilots making flight guidance system inputs, but not verifying the selection on the flight mode annunciator. One report stated: "Both pilots must confirm that any changes via the FCP is verified in the FMA!!!! There was an assumption that the autopilot [had been selected but] was not verified before both pilots began secondary tasks and tertiary tasks" (ASRS, 2014b, report no. 1100710).

Detection. Information regarding who or what first detected the flight path deviation was contained in 104 of the 110 reports. In the vast majority of reports (72 of 104 reports), the primary means of detection was someone or something other than the flight crew. In nearly half (49 of 104) of the reports where detection information was provided, ATC first alerted the crew of the deviation. In 22 of the reports, the primary means of crew notification of the flight path deviation was an onboard alerting system (TAWS, altitude alerter, TCAS, stick shaker, low speed alerting system, overspeed warning, and bank angle alerting).

Consequences. Five reports listed multiple consequences; therefore, the total number of consequences was 119. Table 5 depicts the frequencies of the reported consequences.

Pilot role assignment. Twenty-three of the 25 accident reports provided information regarding who was the PF at the time of the flight path deviation. Of those, the captain was the PF in 15 of the accidents (65\%) while the first officer was the PF in 8 events (35\%). Table 6 provides a distribution of consequences across the various flight phases.

Flight phase. Table 7 shows the flight phase in which the monitoring error led to a flight path deviation. Twenty-two of the 25 flight path deviations (88\%) occurred while the aircraft was in a climb $(n=4)$, descent $(n=1)$, or on approach $(\mathrm{n}=17)$.

Flight parameters not monitored. Table 8 illustrates which flight path parameters were not properly monitored, leading to the flight path deviation. 
Table 5

Consequences of the flight path deviation that arose from inadequate monitoring, as reported in 110 ASRS reports.

\begin{tabular}{ll} 
Consequence & Number of Reports \\
\hline Altitude deviation & 75 \\
Course deviation & 20 \\
Speed deviation & 14 \\
Loss of separation & 2 \\
Well below glideslope & 2 \\
Collision course with ground or obstacle & 2 \\
Other & $4^{\mathrm{a}}$ \\
\hline
\end{tabular}

Note. Consequences are not mutually exclusive; therefore, the total count of consequences exceeded the total number of ASRS reports in the dataset.

a Other categories were: excessive rate-of-descent on approach $(\mathrm{n}=1)$; too low on approach $(\mathrm{n}=1)$; lined up with wrong runway $(\mathrm{n}=1)$; and, excessive angle-of-bank $(\mathrm{n}=1)$. 
Table 6

Distribution by flight phase of consequences resulting from poor monitoring, as reported in 110 ASRS reports.

\begin{tabular}{lccccc} 
Phase & $\begin{array}{c}\text { Altitude } \\
\text { Deviation }\end{array}$ & $\begin{array}{c}\text { Course } \\
\text { Deviation }\end{array}$ & $\begin{array}{c}\text { Speed } \\
\text { Deviation }\end{array}$ & Other & Totals \\
\hline Climb & 19 & 7 & 5 & 4 & 35 \\
Level & 8 & 0 & 1 & 0 & 9 \\
Descent & 41 & 7 & 3 & 0 & 51 \\
Approach & 7 & 6 & 5 & 6 & 24 \\
\hline Totals & 75 & 20 & 14 & 10 & 119 \\
\hline
\end{tabular}

Note. Because some reports cited multiple consequences, the total number of consequences exceeded the total number of ASRS reports. Of the 110 ASRS report, there were 119 consequences.

Table 7

Flight phase in which monitoring error occurred due to lack of flight path monitoring, as reported in 25 aircraft accident reports.

\begin{tabular}{lll}
\hline Flight Phase & Frequency & Percent \\
\hline Climb & 4 & 16 \\
Level Flight & $3^{\mathrm{a}}$ & 12 \\
Descent & 1 & 4 \\
Approach & 17 & 68 \\
\hline Total & 25 & 100 \\
\hline
\end{tabular}


Table 8

Flight path parameter that was inadequately monitored, as found in 25 aircraft accident reports.

\begin{tabular}{lcc}
\hline Flight Path Parameter & Frequency & Percent \\
\hline Airspeed & 10 & 40 \\
Altitude & 6 & 24 \\
Descent rate on approach & 4 & 16 \\
Course on approach & 3 & 12 \\
Bank angle & 2 & 8 \\
\hline Total & 25 & 100 \\
\hline
\end{tabular}

Six of the 17 accidents that occurred on approach were due to crews allowing the aircraft to reach unacceptably low airspeeds. Of the six accidents involving failing to monitor altitude, four involved failing to level-off at the appropriate altitude during an instrument approach. Each of these involved nonprecision instrument approaches. In three accidents the flight crew was looking for the runway during the final stages of a nighttime instrument approach and not adequately monitoring flight path. Two of these involved failing to monitor and level-off at the minimum descent altitude (MDA), and one involved failing to detect and correct an excessive decent rate.

Activities. In six of the 25 accidents, the flight crew was distracted by an aircraft abnormality or malfunction when the flight path deviation occurred.

Contributing factors. Fatigue was cited in five of the accidents. Three accidents involved unanticipated runway reassignment.. Likewise, one accident involving a helicopter enroute to a ship, likely involved crew preoccupation following a destination change.

\section{Discussion}

This section discusses the data analysis of ASRS reports and accident reports. Categories discussed include pilot role assignment, flight deck automation, 
phase of flight in which the flight path deviation occurred, activities the crew was involved in, factors that contributed to poor monitoring, how the deviation was detected, and the consequences of the deviation.

\section{Pilot role assignment}

The research aimed to determine if there was a significant connection between which pilot was flying when the flight path deviation occurred. This interest was prompted by a 1994 NTSB safety study that looked at 37 crewinvolved air carrier accidents. That study found that the captain was the PF in 30 of the 37 accidents (81\%) (NTSB, 1994). As the NTSB (1994) pointed out, pilots typically alternate flying legs, so the disproportionate number of legs for which the captain was the PF as an unexpected result. Likewise, this research intended to explore if a similar pattern may have existed in this study. Table 9 shows that in $56 \%$ of ASRS reports and $65 \%$ of accident reports that provided pilot role information, the captain was the PF.

Table 9

Pilot role in 109 ASRS reports and 23 accident reports where such data was provided.

\begin{tabular}{lcc} 
Report type & Captain & First Officer \\
\hline ASRS data & $61(56 \%)$ & $48(44 \%)$ \\
& & \\
Accident data & $15(65 \%)$ & $8(35 \%)$ \\
\hline
\end{tabular}

Results show there was no statistically difference between accidents and non-accidents in this study's dataset regarding which pilot was the PF when inadequate monitoring led to a flight path deviation.

Although statistical significance may have been lacking, an examination of the numbers in Table 9 indicate that in a higher percentage of cases, the captain was the PF in the ASRS reports and in the accident reports. As noted, disproportionate numbers for captain flying were also reported in NTSB's 1994 safety study. Follow-on research is warranted to determine if first officers may be less effective at monitoring and detecting errors committed by captains. 


\section{Flight deck automation}

The autopilot was engaged in 48 of the 58 ASRS reports that contained information about autopilot engage status. In the accident reports that provided autopilot engage status, 13 of the 17 reports stated the autopilot was engaged when the flight path deviation initially occurred. With modern flight decks where autopilots are used for vast majority of the time, the fact that such a high percentage of cases involved autopilots being engaged is not remarkable. What is noteworthy, however, is that in many cases, the pilots appeared to have relegated flight path control, and hence, monitoring of the flight path, to the automation.

The literature review cited seemingly contradicting information about when someone is a better monitor of automation - when they are actively engaged in the control loop or completely hands-off. This research suggests that both viewpoints are partially correct. "Actively involved in the control loop" doesn't necessarily mean actively engaged in manipulating controls - it means actively engaged mentally with what the automation (or other pilot) is doing and should be doing. This active monitoring process keeps the operator actively engaged in the control loop without having to sacrifice the mental and physical capacity of actually manipulating controls.

\section{Flight phase}

Within each database, the research examined if there were predominate flight phase(s) in which inadequate monitoring led to flight path deviation(s).

Sixty-eight percent of the accidents in this study occurred in a phase of flight that represents only $15 \%$ of flight time, according to flight time estimates by Boeing (2013). This highlights the threat-rich environment that exists on approach, and there is a critical need for heightened monitoring in this flight phase.

The ASRS reports indicated that $92 \%$ of flight path deviations occurred while the aircraft was either in a climb, descent, or approach phase of flight, while $88 \%$ of the accidents were in one of these three flight phases. Furthermore, the flight path deviations occurred during descent or approach in $65 \%$ of ASRS reports and $72 \%$ of accidents.

\section{Activities}

The research explored which predominant activities may have been conducted by the crew shortly before or during the flight path deviation. FMS 
programming, radio communications, scanning for traffic, reading checklists, and other flight-related activities were reported in a number of the ASRS reports. Compared to other activities listed in Table 2, there was a statistically significant difference was found for FMS programming and radio communications/PA announcements $\left(\chi^{2}=14.55, d f=5, p=.012\right)$.

Table 10

Percentage of ASRS reports and accident reports in this study according to flight phase.

\begin{tabular}{lcc} 
Flight Phase & ASRS (\%) & Accidents (\%) \\
\hline Climb & 26 & 16 \\
Level Flight & 8 & 12 \\
Descent & 46 & 4 \\
Approach & 20 & 68 \\
\hline
\end{tabular}

While conduct of these duties is necessary, in several ASRS reports it appears that pilots became consumed in these activities and subsequently failed to adequately scan vital flight instruments. The familiar phrase "aviate, navigate, communicate" must also imply monitoring; if a pilot is not not monitoring, then they are not able to aviate.

Interestingly, when compared to the same data in the ASRS reports, this research discovered a disproportionate number of accidents in which the crew was dealing with an aircraft malfunction when the flight path deviation occurred. Eight of the 78 ASRS reports (10\%) that provided information regarding crew activities mentioned they were dealing with a malfunction. By comparison, in six of the 25 accidents $(24 \%)$ the crew was involved with resolving an aircraft malfunction. The cause of the flight path deviation was not the aircraft abnormality itself, but rather, the distraction associated with the abnormality and the subsequent failure to monitor the flight path. 
After studying 230 ASRS reports where crews reported dealing with aircraft malfunctions, Sumwalt and Watson (1995) suggested that "an aircraft malfunction should serve as an immediate 'red flag' to crewmembers, warning them to be alert against the loss of situational awareness" (p. 6).

\section{Contributing factors}

In 38 ASRS reports pilots described distractions that contributed to their monitoring failures. Although many of the distractions were covered in other categories, it is telling that the word "distraction" was used in 38 of 92 (41\%) reports in which pilots cited factors that contributed to their flight path deviation.

Two significant problems can arise from interruptions: not returning to the original task and returning at a place other than intended, also known as a sequencing error. Testimony received at NTSB's hearing of the 2009 Colgan Air crash stated:

If we're in the middle of a task and something interrupts us, and the interruption is typically very salient, very abrupt, so we turn our attention to this interruption, take care of the interruption, but then after we're finished with that, it is very, very easy to get sucked into the next task in the queue, forgetting that we didn't finish that task that was interrupted. (NTSB, 2009 , p. 580)

\section{Detection}

Monitoring is how we detect deviations from expected parameters. In the accident cases, the errors were not detected before an accident occurred. Therefore, this discussion centers around ASRS data, which revealed that someone or something detected the deviation prior to flight crews in 72 of the 104 reports (69\%) that provided detection information.

Chi-square test goodness of fit revealed a significant result, $\chi^{2}=15.39, d f$ $=1, p<.001$. This underscores that in these cases, crews were not good at monitoring. Keeping these results in perspective, the fact that airplanes aren't crashing daily is indicative of early detection and recovery from flight path deviations by flight crews. Either deviations are not occurring that frequently, or they are caught before accidents or serious excursions occur. 


\section{Consequences}

The consequences in this study ranged from benign events such as altitude deviations that only the air crew noticed, to full-blown accidents that caused loss of life.

One-hundred and ten of the 119 reported consequences (92\%) found in the ASRS data occurred during the combined flight phases of climb, descent, and approach. The majority of the consequences that arose during these combined flight phases were altitude deviations $(n=67)$, the aircraft is transiting through altitudes at high rates of climb or descent.

As shown in Table 6, 24 of the 119 consequences found in the ASRS study occurred during approach. These events involved cases in which crews found themselves well below desired approach speeds, well below glideslope, descending toward the ground with excessive descent rates, descending below the assigned approach altitudes, being on a collision course with obstacles, and being lined-up with wrong runways. Because these events occurred on approach, where there was less altitude to recover from the deviations, the risk for these consequences was potentially higher than if they occurred in different flight phases.

The research examined the possibility of a relationship between flight phase and the consequence. There was a statistically significant result for altitude deviations in descent phase of flight, $\chi^{2}=19.68, d f=3, p<.001$. There were no other statistically significant results.

The parameters that were not monitored varied between ASRS and accidents reports. The largest number of items not monitored in ASRS reports was altitude, as manifested by 75 altitude deviations (68\% of the 110 ASRS reports). For the accident reports in the study, airspeed was the leading category of items not monitored (40\% of 25 accident reports). In fact, all five of the accidents noted in this study which occurred in the past decade involved failure to monitor speed.

Technological advances have helped to prevent many of the types of accidents found in this study. For instance, CFIT accidents have dropped substantially since requirements to install the Terrain Awareness and Warning System (TAWS) have been in place. Moreover, TAWS likely would have prevented 12 of the crashes in this study, had it been installed and operational on the accident aircraft. TAWS is now required for each of the types of aircraft that were involved in those 12 accidents. 
The current last line layer of defense for airspeed monitoring, however, is stall warning systems. Repeated accidents, several of which were those reviewed in this study, show that crews don't always react properly to stall warning. As a result, NTSB has repeatedly called for - alerting systems - warnings that annunciate before the actual stall warning - to notify crews of impending low speed situations. As it stands now, the text implies that low speed situations are alerts that annunciate before the actual stall warning, which is not the correct interpretation.

In summary, the industry has made measurable progress in developing technology to prevent many types of accidents related to failed flight path monitoring. TAWS helps prevent CFIT; ATC and altitude alerters help prevent altitude deviations from becoming larger excursions; Traffic Alert and Collision Avoidance System (TCAS) prevents altitude deviations from becoming midair collisions. What has not been successfully implemented at this point is low speed/low energy alerting systems. The findings of this study suggest a safetyrelated need for development and implementation of low speed/low energy alerting systems.

\section{Findings and Recommendations}

The following findings and recommendations are offered to improve flight path monitoring and increase aviation safety. This study's literature review and data analyses underscore the importance of the need for pilots to plan ahead, get ahead, and stay ahead. Workload management strategies should be developed and incorporated so pilots can monitor at critical junctures in flight. For example, considering the vulnerability of flight path deviations during descent and approach, pilots should plan to brief the approach prior to beginning descent. This includes loading the planned approach into the FMS along with other related activities that can be done in advance. Although this planning may sound intuitive, this research revealed that the pilots in these events did not practice effective workload management strategies. Data show that pilots are, in some cases, pilots relegated aircraft control and the monitoring of flight path, to automation.

The literature that discusses monitoring of automation - whether in the control loop or not - may be misleading. While manually manipulating controls, the pilot is devoting attentional and physical resources to controlling the aircraft, which may allow monitoring to be sacrificed. On the other hand, being too far removed from the control loop may allow the pilot to become disengaged from monitoring. One strategy to keep pilots actively engaged in the control loop comes not necessarily from manually manipulating the controls, but by having pilots "mentally flying" the aircraft when automation (or the other pilot) is flying. This 
can be accomplished by having the pilot callout anticipated FMA changes before they occur, instead of waiting for them to occur. This is similar to an approach that USAir developed in the early 1990's for altitude callouts, where the pilot was directed to make the callout prior to sounding of the altitude alerter. This forced the pilot to remain actively engaged with altitude monitoring. If a callout was missed, this type of arrangement would require immediate feedback to the pilot to indicate that their monitoring had lapsed (Sumwalt, 1995). Lastly, having pilots point to the FMA to confirm proper annunciation appearance is another way of keeping them in the control loop.

According to this study, crews were particularly vulnerable to flight path deviations during the descent and approach phases of flight. The descent and approach phases of flight in this study were particularly vulnerable to flight path deviations. Pilots should treat these areas with particular caution, including extending sterile cockpit-like procedures to include the entire descent phase. Procedural designers should review procedures and non-monitoring tasks should be re-scheduled, if possible, to different flight phases so they that don't conflict with monitoring during these critical phases. For example, one airline moved a 10,000 foot PA announcement to top-of-descent to avoid having a split cockpit during later stages of descent. Given that low airspeed situations continue to pose problems for aviation safety, low speed/low energy alerting systems should be developed and installed.

Follow-on research is needed to determine if first officers are less effective than captains at monitoring and detecting flight path deviations made by captains. FAA's training rule requires that by March 2019, air carrier training programs must include training on monitoring. Although determining the best means of training is not within the scope of this paper, information gleaned in the literature review indicates that simply presenting monitoring information via PowerPoint presentations should not be the only training method. It must be stressed during simulator training where pilots have the opportunity to practice workload management and optimal monitoring skills. In this regard, Dismukes stated: "You've got to practice it repetitively until it's automatic and then you've got to check it" (NTSB, 2009, pp. 583-584).

The reviewed literature indicated that pilots may not fully understand what automation modes are telling them. If pilots don't understand what it is doing or should be doing, they can't properly monitor it. Just as a type rating oral exam quizzes pilots extensively on systems knowledge, the oral exams should spend a considerable amount of time quizzing the pilot on FMA indications. The pilot 
candidate should be able to state with precision explicitly what FMA modes should be indicated for each phase of flight.

Monitoring is a very broad term. Some have indicated that when pilots hear the term "monitoring," it means different things to different people (J. Klinect, personal conversation, November 20,2012). As a result, the emphasis on flight path monitoring may have gotten lost. Captain John Cashman, formerly Boeing's chief test pilot and director of flight operations, suggests a more descriptive term may be "instrument scanning" to clearly spell-out that the focus is on the basic instrument scan of flight path instruments, and not necessarily on monitoring aircraft systems, the actions of other pilots, ATC, etc. (J. Cashman, personal conversation, June 23, 2014). 


\section{References}

Aviation Safety Reporting System. (2014a). ASRS program briefing. Retrieved from http://asrs.arc.nasa.gov/docs/ASRS_ProgramBriefing2013.pdf

Aviation Safety Reporting System. (2014b). Search request no. 7173. Flight crew cockpit monitoring/scanning related incidents. Moffett Field, CA: Aviation Safety Reporting System.

Boeing. (2013). Statistical summary of commercial jet airplane accidents, worldwide operations, 1959-2012. Retrieved from http://www.boeing.com/news/techissues/pdf/statsum.pdf

Flight Safety Foundation. (2014). A practical guide for improving flight path monitoring. Retrieved from http://flightsafety.org/current-safetyinitiatives/flight-path-monitoring

Jentsch, F., Martin, L., \& Bowers, C. (1997). Identifying critical training needs for junior first officers. (Technical report submitted to the Naval Air Warfare Center Training Systems Division and the Office of the Chief Advisor for Human Factors at the Federal Aviation Administration, AAR100). Orlando, FL: University of Central Florida.

Loukopoulos, L., Dismukes, K., and Barshi, E. (2009). The multitasking myth: Handling complexity in real-world operations. Surrey, England: Ashgate.

Mack, A., \& Rock, I. (1998). Inattentional blindness. Cambridge, MA: The MIT Press.

National Archives and Records Administration. (2013, November 12). Department of Transportation, Federal Aviation Administration, 14 CFR Part 121 Qualification, service, and use of crewmembers and aircraft dispatchers; final rule. Federal Register (78), 218. Retrieved from http://www.gpo.gov/fdsys/granule/FR-2013-11-12/2013-26845

National Safety Council. (2012). Understanding the distracted brain: Why driving while using hands-free cell phones is risky behavior. Retrieved from http://www.nsc.org/safety_road/Distracted_Driving/Documents/Cognitive \%20Distraction\%20White\%20Paper.pdf 
National Transportation Safety Board. (1973). Aircraft accident report: Eastern Air Lines, Inc., L-1011, N310EA, Miami, FL., December 29, 1972. (NTSB Report No. NTSB/AAR-73/14). Washington, DC: Author. Retrieved from http://libraryonline.erau.edu/online-full-text/ntsb/aircraft-accidentreports/AAR73-14.pdf

National Transportation Safety Board. (1994). Safety study: A review of flight crew-involved, major accidents of U.S. air carriers, 1978 through 1990. (NTSB Report No. NTSB/SS-94/01). Washington, DC: Author. Retrieved from http://libraryonline.erau.edu/online-full-text/ntsb/safety-

National Transportation Safety Board. (2009). Public hearing in the matter of: Colgan Air, Inc. Flight 3407, Bombardier DHC-400, N200WQ, Clarence Center, New York, February 12, 2009. Thursday, May 14, 2009. Retrieved from http://dms.ntsb.gov/pubdms/search/document.cfm? docID $=314281 \&$ docketID $=47271 \&$ mkey $=73351$

Nikolic, M., Orr, J., \& Sarter, N. (2004). Why pilots miss the green box: How display context undermines attention capture. International Journal of Aviation Psychology, 14(1), 39 -52.

Parasuraman, R., Mouloua, M., \& Malloy, R. (1996). Effects of adaptive task allocation on monitoring automated systems. Human Factors, 38(4), 665679. doi: $10.1518 / 001872096778827279$

Parasuraman, R., Sheridan, T., \& Wickens, C. (2000). A model for types and levels of human interaction with automation. IEEE Transactions on systems, man, and cybernetics - Part A: Systems and humans, 30(3), 286297.

Raby. M., \& Wickens , C. (1994). Strategic workload management and decision biases in aviation. International Journal of Aviation Psychology, 4(3), 211-240, doi: 10.1207/s15327108ijap0403_2

Sumwalt, R. (1995). Altitude awareness programs can reduce altitude deviations. Flight Safety Digest, 14(12), 1-10. Retrieved from http://flightsafety.org/fsd/fsd_dec95.pdf

Sumwalt, R., \& Watson, A. (1995). ASRS incident data reveal details of flightcrew performance during malfunctions. Flight Safety Digest, 14(10), 1-7. Retrieved from http://flightsafety.org/fsd/fsd_oct95.pdf 
Teichner, W. (1974). The detection of a simple visual signal as a function of time of watch. Human Factors, 16(4), 339-353.

Warm, J., Parasuraman, R., \& Matthews, G. (2008). Vigilance requires hard mental work and is stressful. Human Factors: The Journal of the Human Factors and Ergonomics Society, 50(3), 433-441. doi:10.1518/001872008X312152

Wicken, C., Santamaria, A., \& Sebok, A. (2013). A computational model of task overload management and task switching. In Proceedings of the Human Factors and Ergonomics Society Annual Meeting 2013, 57, 763 - 767. doi:10.1177/1541931213571167 